\title{
PERANCANGAN SISTEM INFORMASI PENGELOLAAN ANGGARAN KARYAWAN PADA PT SUMBER CEMERLANG KENCANA PERMAI
}

\author{
Achmad Ridwan Baidhawi ${ }^{1}$, Intan Mutia², Jonser Sinaga ${ }^{3}$ \\ ${ }^{1,2,3}$ Universitas Indraprasta PGRI \\ Jalan Raya Tengah No 80, Kelurahan Gedong, Pasar Rebo, Jakarta Timur \\ 로aidhawi50@gmail.com, 22as.syifaraa@gmail.com, ${ }^{3}$ jonser_s@yahoo.com
}

\begin{abstract}
ABSTRAK
PT. Sumber Cemerlang Kencana Permai masih melakukan pencatatan anggaran karyawan secara manual, padalah pengolahan data anggaran keuangan karyawan membutuhkan ketelitian yang lebih dan waktu yang cukup lama untuk proses pembuatan dan penyampaian laporan. Hal ini semakin meningkatkan kompleksitas pekerjaan bagian finance. Tujuan penelitian ini adalah merancang sistem informasi pengelolaan data dan laporan anggaran karyawan pada PT. Sumber Cemerlang Kencana Permai untuk memudahkan proses pengelolaan data dan laporan anggaran karyawan agar mempermudah dan mempercepat proses pencarian data anggaran karyawan. Metode penelitian menggunakan metode grounded research yang memiliki landasan fakta dan menggunakan analisis perbandingan dengan cara pengumpulan dan menganalisa data pada waktu yang bersamaan dengan observasi dan wawancara. Hasil yang dicapai adalah memudahkan karyawan dalam proses pengajuan anggaran, dan meningkatkan kinerja finance dalam proses pengelolaan data anggaran karyawan dimana data dapat dikelola dengan mudah dan cepat. Data anggaran karyawan yang sudah tersimpan serta terintegrasi dengan rapih ke dalam suatu database, sehingga mempermudah proses pencarian dan membuat laporan data anggaran karyawan perusahaan.
\end{abstract}

Kata Kunci: Sistem Informasi, Pengelolaan, Anggaran Karyawan.

\begin{abstract}
PT. Sumber Cemerlang Kencana Permai still records employee budgets manually, at which time the processing of employee financial budget data requires more accuracy and a long enough time for the process of making and submitting reports. This further increases the complexity of the finance section work. The purpose of this research is to design data management information systems and employee budget reports at PT. Sumber Cemerlang Kencana Permai to facilitate the process of managing data and employee budget reports to facilitate and speed up the process of finding employee budget data. Research methods use grounded research methods that have a basis of facts and use comparative analysis by collecting and analyzing data at the same time as observations and interviews. The results achieved are to facilitate employees in the budget submission process, and improve financial performance in the process of managing employee budget data where data can be managed easily and quickly. Employee budget data that has been stored and neatly integrated into a database, thus simplifying the search process and making reports of company employee budget data.
\end{abstract}

Key Word: Information Systems, Management, Employee Budget.

\section{PENDAHULUAN}

PT. Sumber Cemerlang Kencana Permai (PT. SCKP) merupakan perusahaan yang bergerak di salah satu bidang kontraktor telekomunikasi, perusahaan ini telah menggunakan fasilitas komputer dalam menjalani kegiatan untuk memecahkan masalah.

Dalam permasalah pengolahan data keuangan sebagian besar media penyimpanan data-data keuangan masih berupa kertas dan buku, maka keamanan dari dokumen itu kurang terjamin dan mempunyai banyak kelemahan antara lain mudah terbakar, lembab dan tidak tahan lama.
Dalam mewujudkan kualitas Perusahaan membutuhkan pengelolaan sumber daya internal perusahaan yang komprehensif dan profesional. Salah satu sumber daya dalam sebuah perusahaan butuh pengelolaan yang baik adalah masalah keuangan. Untuk dapat memberikan suatu solusi terbaik terhadap perusahaan PT. Sumber Cemerlang Kencana Permai, maka perlu dibangun sistem informasi mengelola Anggaran Karyawan Pada PT. Sumber Cemerlang Kencana Permai

Perancangan sistem memiliki arti dari tahapan setelah analisis melalui siklus pengembangan sistem, hasil dari devinisi pada fungsionalis, 
suatu hal yang di persiapan untuk kebutuhan rancanangan bangunan implementasi, dan penggambaran dibentuknya suatu sistem termasuk mengkonfirmasi komponenkomponen pada perangkat lunak dan perangkat keras dari suatu sistem. (Nopriandi, 2018)

Berdasarkan (Sutabri, 2012), Informasi dapat dikatakan sebagai sebuah data yang telah diklasifikasi atau diinterprestasi agar dapat digunakan pada suatu proses pengambilan keputusan.

"Unified Modelling Language selanjutnya disebut $U M L$ adalah metode pengembangan pada suatu sistem yang menggunakan bahasa grafis sebagai alat untuk mendokumentasikan dan menginplementasikan spesifikasi sistem." (Sri Mulyani \& Sis, 2017)

"Use Case Diagram, yaitu diagram yang menggambarkan hubungan antara sistem dengan aktor. Diagram ini hanya menggambarkan suatu sistem secara global. Karena use case diagram hanya menggambarkan sistem secara global, maka elemen - elemen yang dapat digunakan hanya sedikit." (Sri Mulyani \& Sis, 2017)

"Class diagram memperlihatkan interaksi antara class pada sistem. Class berisi informasi dan perilaku yang dimiliki oleh class tersebut." (Saputra, 2020)

"Database adalah sekumpulan data yang disimpan didalam suatu aplikasi. Pada setiap database, memiliki API yang spesifik untuk dapat membuat, mengakses, mengatur, mencari, dan menyalin suatu data yang berada di dalamnya." (Enterprise, 2014)

"Netbeans adalah Integrated Development Environment (IDE) berbasiskan Java dari Sun Microsystems yang berjalan di atas Swing. Swing adalah suatu teknologi Java untuk mengembangkan aplikasi berbasis Desktop yang dapat berjalan di berbagai macam platforms seperti Windows, Linux, Mac OS X and Solaris. IDE adalah sesuatu yang di integrasikan ke dalam suatu aplikasi perangkat lunak yang berada pada ruang lingkup pemrograman yang menyediakan pembangunan Graphic User Interface (GUI), suatu text atau kode editor, suatu compiler atau interpreter dan suatu debugger." (Haqi, 2019)
Tujuan pada penelitian yang dilakukan untuk dapat memberikan aplikasi interface yang dapat memudahkan dalam proses pengelolaan data anggaran karyawan, mengurangi tingkat kesalahan dalam hal peng-inputan dan pengeloaan data informasi anggaran, mempermudah proses pencarian data anggaran dan mempermudah proses pembuatan data laporan pengajuan karyawan dengan lebih akurat dan waktu yang cepat sehingga pekerjaan user dapat lebih optimal.

Manfaat dari penelitian ini adalah menghasilkan sebuah aplikasi pengelolaan anggaran karyawan yang user friendly untuk dapat menigkatkan kinerja finance, mempermudah bagi karyawan untuk dapat melakukan pengajuan anggaran, mempermudah finance dalam proses pengeleloaan data anggaran, dan mempermudah finance dalam proses pembuatan laporan dengan cepat dan akurat

\section{METODE PENELITIAN}

Metode penelitian yang penulis gunakan adalah metode grounded research atau disebut metode theory "Grounded theory adalah metodologi umum untuk mengembangkan teori. Berbasis pengumpulan dan analisis data pada pengembangan teori Metodologi. Ini disebut grounded theory, dan model penelitiannya disebut grounded research. Penemuan teori dari data empiris yang diperoleh secara sistematis dalam penelitian sosial merupakan pokok bahasan metodologi penelitian kualitatif model penelitian membumi." (Adibah, 2018)

Lokasi penelitian serta pengamatan dalam proses pengambilan atau pengumpulan data yang menunjang proses penelitian ini bertempat di kantor pusat PT. Sumber Cemerlang Kencana Permai yang beralamat Jalan Kebon Jeruk Permai Blok Aa.1 No.20, RT.19/RW.7, Meruya Selatan, Kecamatan Kembangan, Kota Jakarta Barat, Daerah Khusus Ibukota Jakarta 11610. Telp : (021) 5846803 - 5873314 Fax. (021) 5873313, Email: project@ @sckp.co.id.

Pengumpulan data dalam penelitian ini menggunakan metode atau teknik yang diterapkan sehingga pengguna dapat mendemonstrasikannya melalui angket, 
wawancara, observasi, tes dokumen, dll.(Gainau, 2016)

Untuk menyempurnakan hasil dari penelitian ini, penulis mencoba menuliskan langkahlangkah yang dilakukan dalam membuat pengembangan dan perancangan sistem, maka digunakan metode terstruktur dengan paradigma siklus hidup klasik (classic life cycle) atau metode air terjun (waterfall).

Menurut (Lusia Violita Aprilian, 2020) Metode air terjun atau yang sering dinamakan siklus hidup klasik (classic life cycle), menjelaskan metode pengembangan perangkat lunak yang sistematis dan berurutan, dimulai dari spesifikasi kebutuhan pengguna, kemudian dilanjutkan melalui tahapan perencanaan, pemodelan, konstruksi, dan pengiriman sistem kepada pengguna (deployment), dan akhirnya Dukungan perangkat lunak yang dihasilkan lengkap.

Paradigma siklus hidup klasik untuk pengembangan sistem diilustrasikan seperti pada gambar berikut :

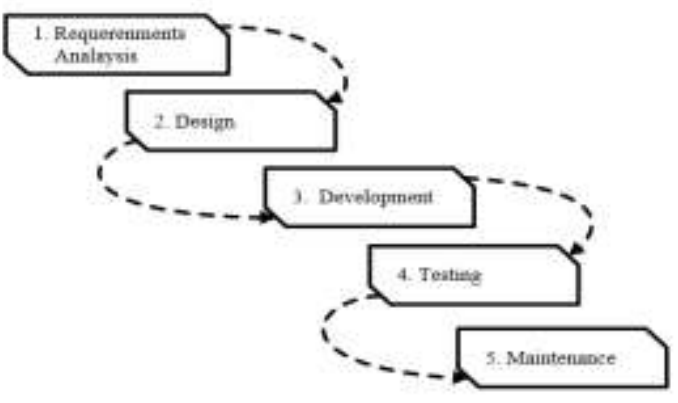

Gambar 1. Tahapan Metode Waterfall Sumber : (Lusia Violita Aprilian, 2020)

\section{HASIL DAN PEMBAHASAN}

Setelah mengetahui dan menganalisa sistem yang berjalan pada perusahaan PT. SCKP maka peneliti memberikan usulan sistem dan aturan bisnis dalam sistem pengelolaan anggaran karyawan, sebagai berikut :

1. Proses pendataan Karyawan/Staff

a. Masing-masing staff dan Cooperation PIC memiliki ID.

b. Jika staff dan cooperation pic masih belum terdaftar kedalam sistem perusahaan, maka administrator perusahaan akan mendaftarkan kedalam sistem untuk memiliki ID

c. Data Staff dan Coorperation PIC hanya dapat di kelola oleh bagian administrator utama dan Finance pada PT. SCKP.

2. Proses Pengajuan Anggaran

a. Staff dan coorperation pic (orang borongan) dapat melakukan login pada aplikasi anggaran dan mengajukan anggaran, baik anggaran putih atau merah sesuai dengan kebutuhan

b. Access pada aplikasi anggaran, staff dan coorperation pic dibatasi hanya dapat melakukan pengajuan anggaran dan mengecek data Approval Anggaran.

c. Accses Form Approval di miliki oleh Staff yang memiliki jabatan tertentu, seperti Project Manager, General Manager, Manager Finance, Direktur Finance, dan Director.

3. Proses Laporan Anggaran

a. Laporan pada sistem anggaran ini terdiri dari laporan data staff, laporan data pengajuan anggaran, laporan data approval anggaran, dan laporan pengeluaran anggaran perusahaan.

b. Laporan data pengajuan anggaran pada pada aplikasi anggaran ini juga terdapat parameter data, yang mana akan dibagi menjadi 3 bagian, yaitu Daily Report, Weekly Report, dan Monthly Report.

c. Laporan Anggaran dapat di akses oleh Staff Finance, Manager Finance, Direktur Finance, Project Manager, General Manager dan Director.

Berikut adalah gambaran pada sistem berjalan dalam bentuk Dekomposisi fungsi sistem yang diusulkan :

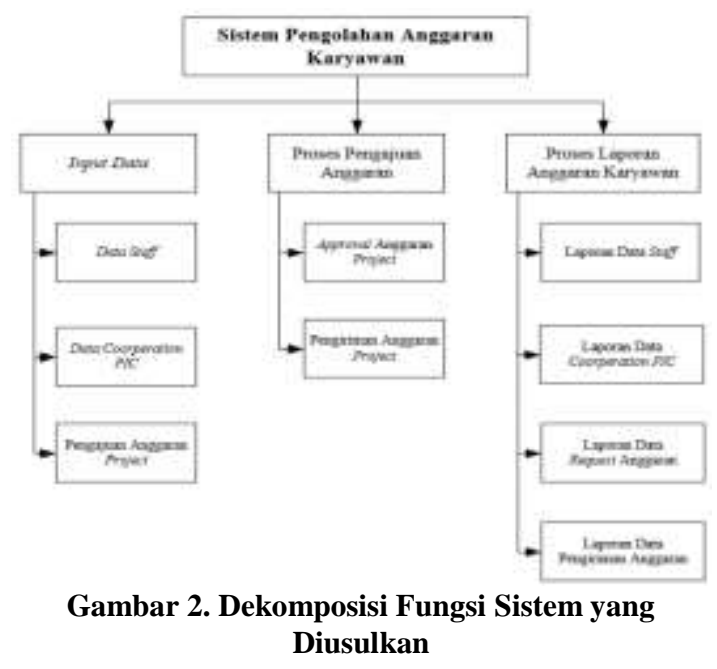

Use Case Diagram

Use case adalah teknik untuk merekam kebutuhan fungsional dari sebuah sistem. Use 
case menggambarkan interaksi khas antara pengguna sistem dan sistem itu sendiri dengan memberikan deskripsi tentang bagaimana sistem digunakan.

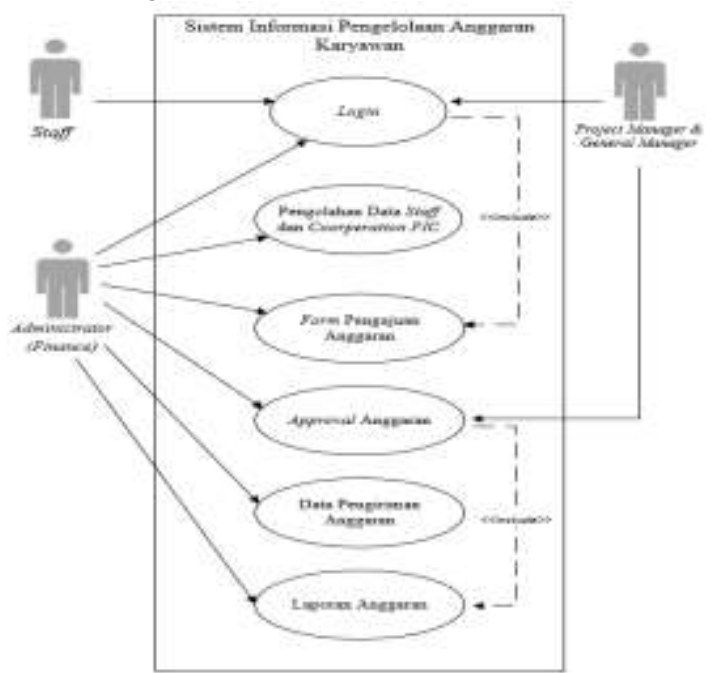

Gambar 3. Use Case Diagram Sistem yang Diusulkan

\section{Class Diagram}

Class Diagram merupakan subuah Class yang menggambarkan Struktur dan penjelasan objek, class, paket, serta hubungan satu sama lain. Adapun class diagram tahap perencanaan adalah sebagai berikut :

Tabel 1. Spesifikasi Stereotype Class Tingkat Perancangan

\begin{tabular}{|c|c|c|}
\hline $\begin{array}{c}\text { Class } \\
\text { Boundary }\end{array}$ & Class Control & Class Entity \\
\hline Form staff & $\begin{array}{l}\text { Add, edit, delete } \\
\text { staff }\end{array}$ & Administrator \\
\hline $\begin{array}{l}\text { Form } \\
\text { Coorperation }\end{array}$ & $\begin{array}{l}\text { Add, edit, delete } \\
\text { Coorperation }\end{array}$ & Administrator \\
\hline $\begin{array}{l}\text { Form } \\
\text { Anggaran }\end{array}$ & $\begin{array}{l}\text { Add, edit, delete } \\
\text { Coorperation }\end{array}$ & Staff \\
\hline $\begin{array}{l}\text { Form } \\
\text { Approval }\end{array}$ & $\begin{array}{l}\text { Add, update } \\
\text { Approval }\end{array}$ & $\begin{array}{l}\text { Administrator, } \\
\text { Project } \\
\text { Manager, } \\
\text { General } \\
\text { Manager, dan } \\
\text { Finance } \\
\end{array}$ \\
\hline $\begin{array}{l}\text { Form } \\
\text { Transaksi }\end{array}$ & $\begin{array}{l}\text { Add, update } \\
\text { Transaksi }\end{array}$ & $\begin{array}{l}\text { Administrator } \\
\text { dan Finance }\end{array}$ \\
\hline
\end{tabular}

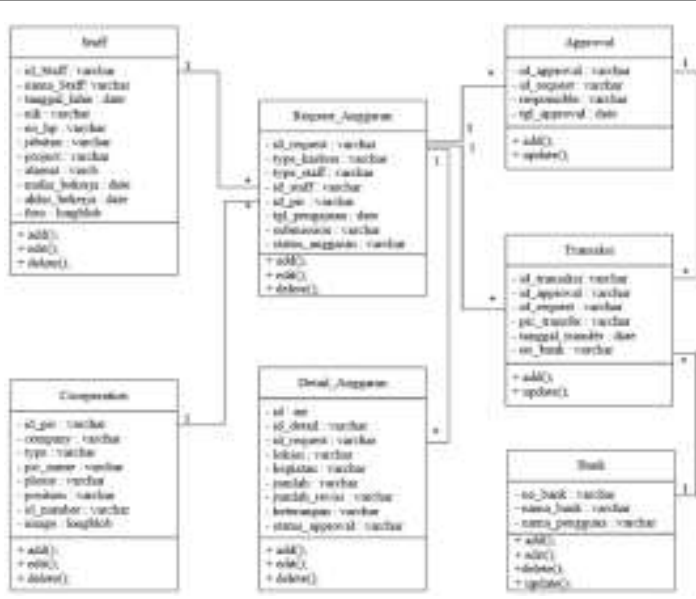

Gambar 4. Diagram Kelas Sistem yang Diusulkan

\section{Entity Relationship Diagram}

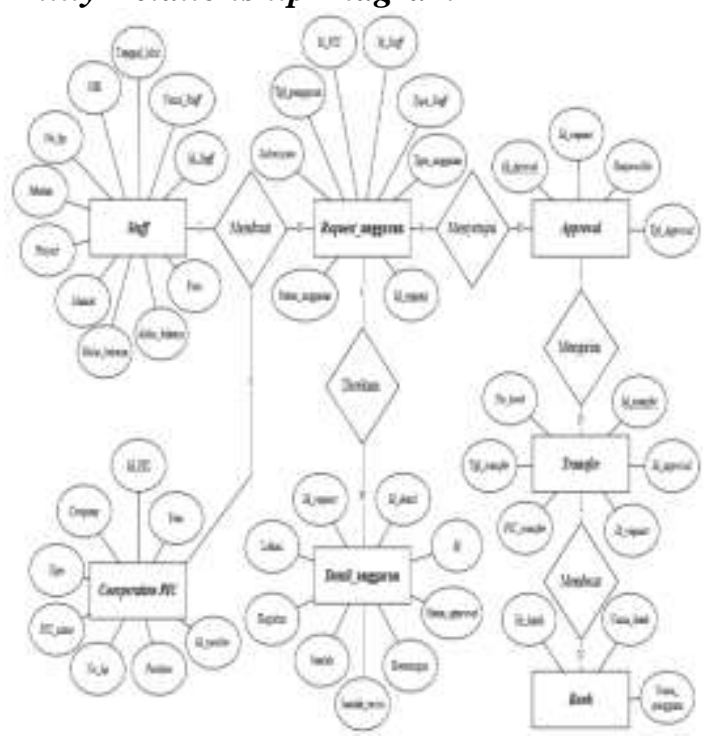

Gambar 5. Entity Relationship Diagram yang Diusulkan

Dari gambaran diagram yang diusulkan, selanjutnya di implementasikan kedalam sistem yang menghasilkan suatu aplikasi dengan tampilan layar sebagai berikut :

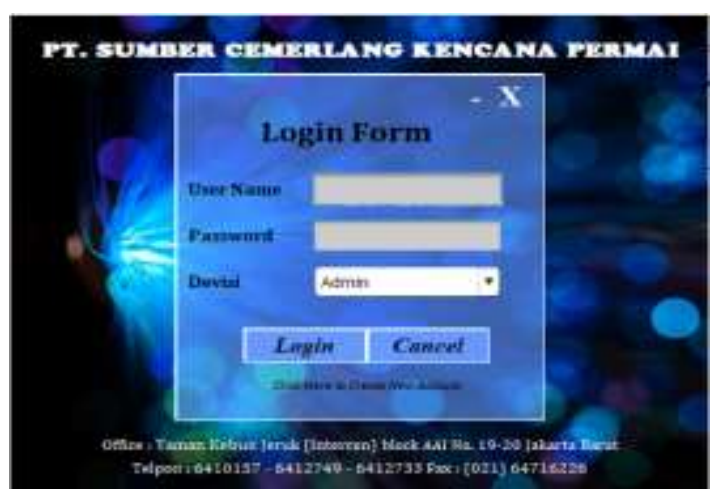

Gambar 6. Tampilan Layar Form Login

Tampilan ini terdapat pada awal program. Form Login dirancang untuk dapat dikelola dengan baik dengan membedakan sistem 
dengan login dari bagian setiap masing masing divisi yang memiliki hak dan kewenangan berbeda.

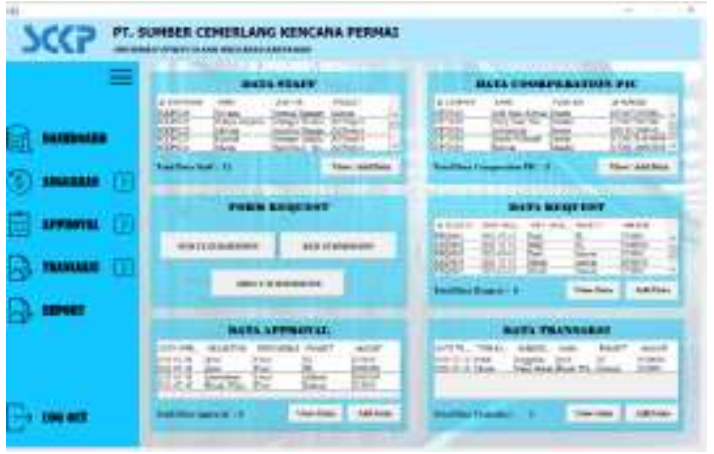

Gambar 7. Tampilan Layar Dashboard

Tampilan ini adalah halaman dashboard atau halaman utama pada aplikasi pengelolaan anggaran karyawan, dimana pada tampilan dashboard terdapat data-data aplikasi yang sudah tersimpan pada database dan di tampilkan pada tabel halaman dashboard.

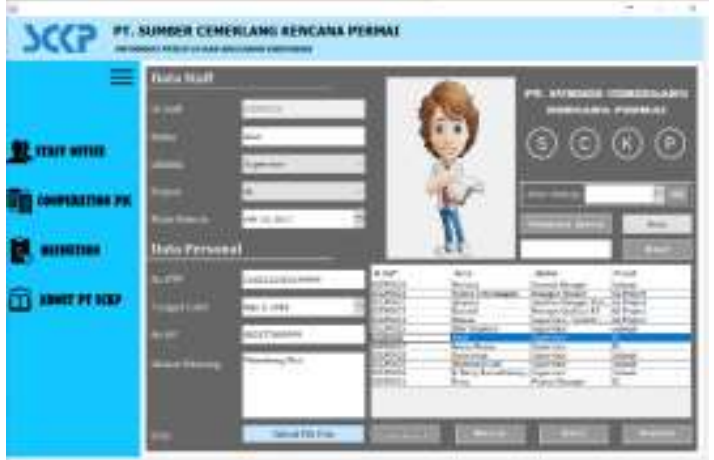

Gambar 8. Tampilan Layar Dashboard

Tampilan ini merupakan halaman data staff, pada halaman ini, hanya user yang memiliki kewenangan pada devisi seperti Administrator, dan Finance yang dapat melakukan pengelolaan data staff, dengan menambah data, menghapus data, dan juga mengedit data staff.

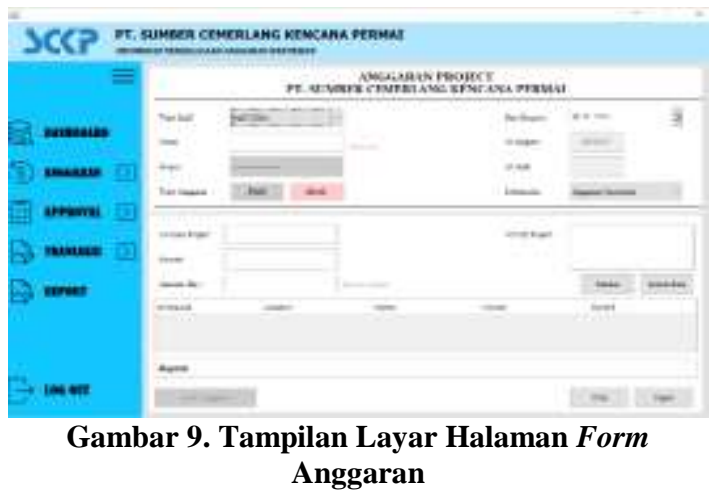

Halaman ini merupakan tampilan form Anggaran, pada proses ini user pada semua divisi dapat mengaksesnya, user dapat melakukan pengajuan anggaran pada form anggaran ini, dengan pilihan type anggaran putih atau merah.

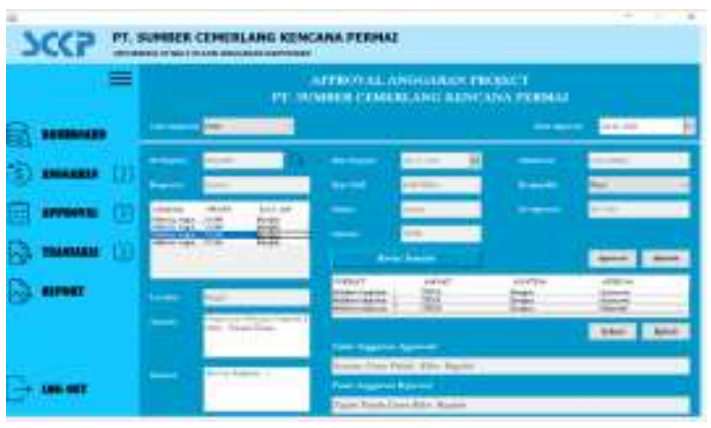

Gambar 10. Tampilan Layar Halaman Form Approval

Pada tampilan layar ini merupakan halaman form approval anggaran karyawan. Pada halaman ini hanya beberapa user yang memiliki kewenangan untuk dapat mengakses, seperti divisi Project Manager, General Manager, Manager Finance, Director Finance, dan Director. Pada proses approval anggaran, user type anggaran (putih dan merah), kemudian memilih data anggaran pada тепи рор-up yang akan ditampilkan setelah klik tombol "search", kemudian user dapat memilih anggaran yang akan dilakukan approval, dan klik tombol "Approved" untuk menyetujui anggaran atau klik tombol "Rejected" untuk menolak anggaran.

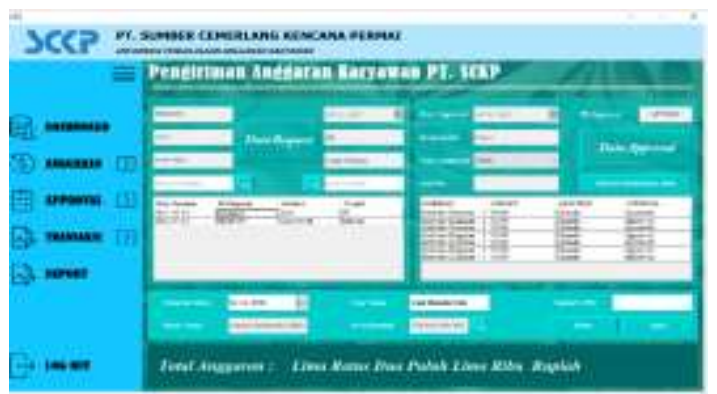

Gambar 11. Tampilan Layar Halaman Form Transaksi

Tampilan layar ini merupakakn halaman form Transaksi, pada halaman ini hanya user dengan devisi Finance yang dapat mengakses dan melakukan pengelolaan proses Transaksi. Pada halaman ini user dapat memilih data table request anggaran yang sudah full approved, kemudian user dapat memilih nomer rekening dengan klik tombol "search" untuk dapat menampilkan pop-up data nomer rekening bank dan nama bank yang sudah tersimpan pada database. Kemudian user 
dapat klik tombol "kirim" untuk dapat mengirim anggaran karyawan.

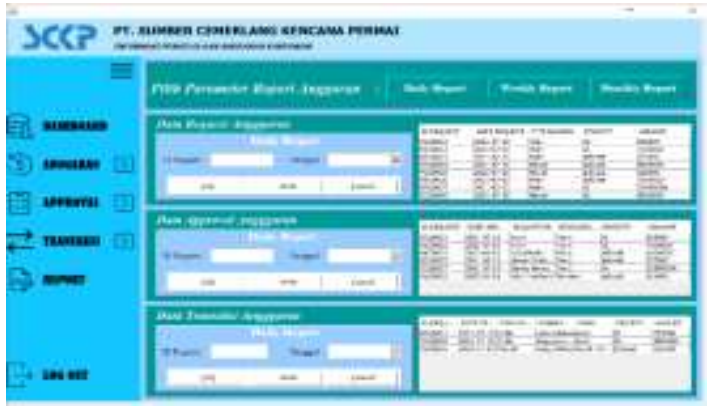

Gambar 12. Tampilan Layar Halaman Menu Report

Layar diatas menampilkan tampilan halaman Menu Report. Pada halaman ini data request anggaran, approval anggaran, dan transaksi anggaran, dan pada masing-masing data anggaran, user dapat memilih dengan parameter yang disediakan, seperti daily report, weekly report, dan monthly report, setelah itu user dapat klik tombol "Print" untuk dapat mencetak laporan anggaran.

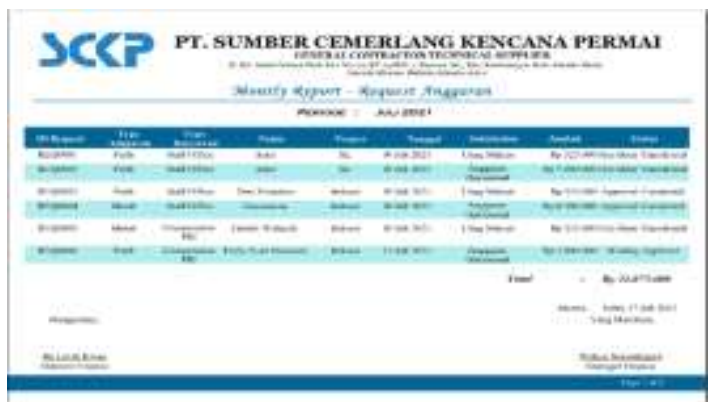

Gambar 13. Tampilan Layar Monthly Report - Data Request

Tampilan Monthly Report pada data Request Anggaran karyawan yaitu menampilkan keseluruhan data request anggaran karyawan pada bulan yang telah di tentukan untuk dapat mengecek laporan total request anggaran karyawan pada periode bulan tersebut.

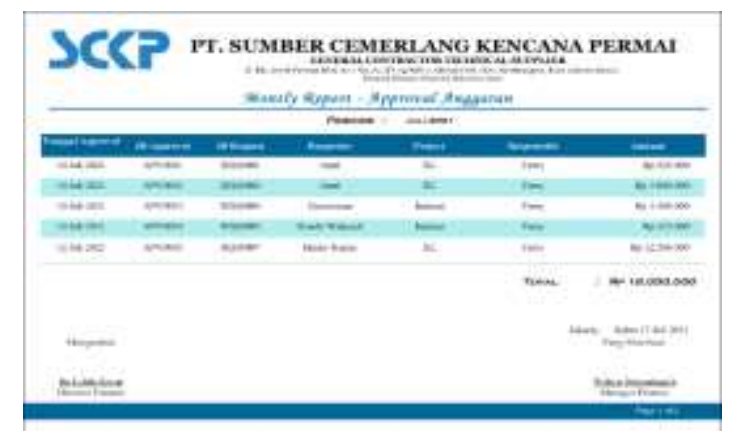

Gambar 14. Tampilan Layar Monthly Report - Data Approval

Tampilan Monthly Report pada data approval anggaran karyawan, yaitu menampilkan data approval anggaran karyawan pada periode bulan yang telah ditentukan untuk mengetahui total anggaran yang sudah mendapatkan approved pada periode bulan tersebut.

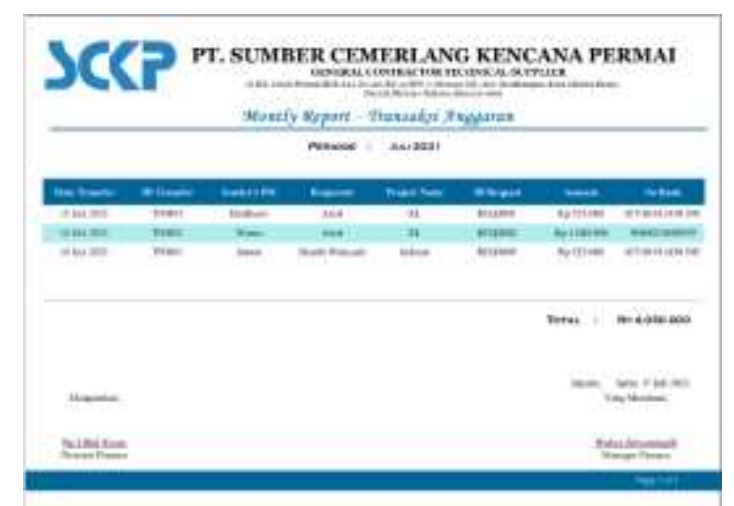

Gambar 15. Tampilan Layar Monthly Report - Data Transaksi

Tampilan Monthly Report pada data transaksi anggaran karyawan, yaitu menampilkan data transaksi anggaran seluruh karyawan untuk mengetahui total anggaran karyawan yang sudah dilakukan transaksi pada periode bulan tersebut.

\section{SIMPULAN DAN SARAN}

Berdasarkan pada tahap-tahap penelitian yang telah dilakukan dalam menganalisis Perancangan Sistem Informasi Pengelolaan Anggaran Karyawan Pada PT. Sumber Cemerlang Kencana Permai, yang memiliki sistem keuangan informasi berbasis komputer dengan fungsi untuk mencatat dan mengolah data keuangan yang ada untuk kemudian disajikan dalam bentuk laporan keuangan. penulis dapat menarik kesimpulan bahwa dengan sistem informasi yang dibuat mampu memberikan solusi pada permasalahan yang terjadi yakni pengolahan data dan pembuatan laporan.

Dengan dibuatnya sistem yang user friendly memudahkan finance untuk mendata proses request anggaran, approval anggaran, dan transaksi anggaran karyawan dengan lebih cepat dan akurat.

Dengan menggunakan aplikasi sistem ini penyimpanan dan pengarsipan data akan lebih mudah dan rapih

Saran yang diharapkan adalah perlunya pengadaan sarana dan prasana yang menunjang dalam pemakaian aplikasi penerimaan ini, seperti adanya fasilitas 
hardware dan software yang akan menunjang pemakaian aplikasi informasi pengelolaan anggaran ini serta pengarahan kepada user (brainware) dalam penggunaan aplikasi ini agar penggunaan aplikasi informasi pengelolaan anggaran ini akan dirasakan lebih optimal.

\section{UCAPAN TERIMAKASIH}

Peneliti menyampaikan rasa hormat dan terima kasih kepada semua pihak yang dengan tulus memberikan bantuan dan dorongan kepada peneliti untuk menyelesaikan jurnal ini dan terima kasih kepada Jurnal Seminar Nasional Riset dan Inovasi Teknologi (SEMNAS RISTEK) 2022 untuk artikel ilmiah ini.

\section{DAFTAR PUSTAKA}

Adibah, I. Z. (2018). Metodologi Grounded Theory. Jurnal Inspirasi, 2(2), 147-166. http://download.garuda.ristekdikti.g o.id/article.php?article $=1280091 \&$ va $1=17071 \&$ title $=$ Metodologi

Grounded Theory

Enterprise, J. (2014). MySQL untuk Pemula. Elex Media Komputindo. https://books.google.co.id/books?id $=\% 5$ C_ExJDwAAQBAJ

Gainau, M. B. (2016). Pengantar Metode Penelitian. PT Kanisius. https://books.google.co.id/books?id $=\mathrm{L} 40 \mathrm{pEAAAQBAJ}$

Lusia Violita Aprilian, M. Y. H. S. M. H. K. S. (2020). Memahami Metode Omax dan Promethee pada Sistem Pendukung Keputusan. CV. Kreatif Industri Nusantara. https://books.google.co.id/books?id $=$ IIr9DwAAQBAJ

Nopriandi, H. (2018). Perancangan Sistem Informasi Registrasi Mahasiswa. Jurnal Teknologi Dan Open Source, 1(1), 73-79. https://doi.org/10.36378/jtos.v1i1.1

Saputra, M. H. K. (2020). Panduan Pembuatan Aplikasi Monitoring Dan Penilaian Kinerja Pengembangan Talent Pada Perusahaan. Kreatif. https://books.google.co.id/books?id $=\mathrm{G} 2 \mathrm{bsDwAAQBAJ}$
Sri Mulyani, A. C. A., \& Sis, A. (2017). Analisis dan Perancangan Sistem Informasi Manajemen Keuangan Daerah: Notasi Pemodelan Unified Modeling Language (UML). Abdi Sistematika. https://books.google.co.id/books?id $=\% 5 C_{-}$7nPDgAAQBAJ

Sutabri, T. (2012). Konsep Sistem Informasi. Penerbit Andi. https://books.google.co.id/books?id $=\mathrm{uI} 5 \mathrm{eDwAAQBAJ}$ 